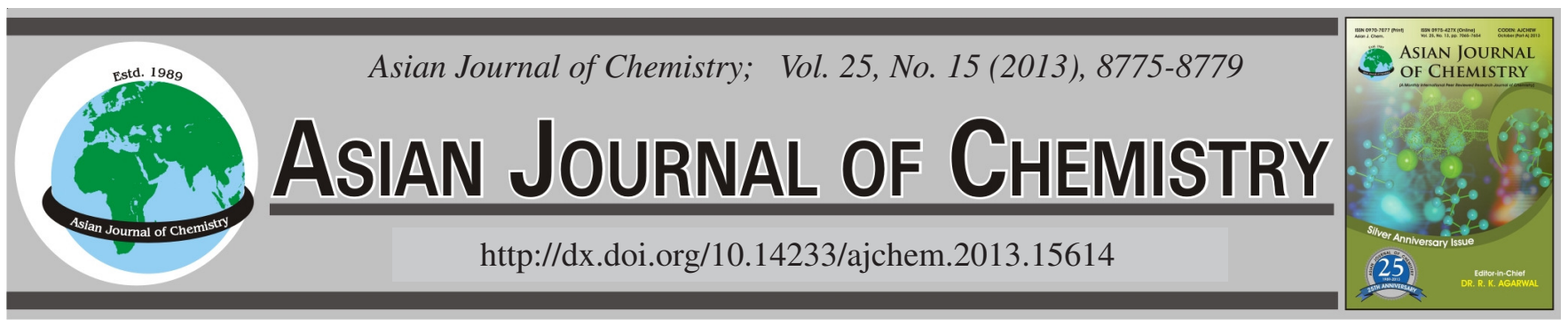

\title{
Preparation and Characterization of Inclusion Complex of Carbosilane Dendrimers and Cyclodextrins
}

\author{
Lin Zhu ${ }^{1,2}$, Huashi LiU ${ }^{2}$, Ruifang Guan ${ }^{1,2, *}$ and Chuanjian Zhou ${ }^{3, *}$
}

${ }^{1}$ Shandong Provincial Key Laboratory of Preparation and Measurement of Building Materials, Jinan 250022, P.R. China

${ }^{2}$ School of Material Science and Engineering, University of Jinan, Jinan 250022, P.R. China

${ }^{3}$ School of Material Science and Engineering, Shandong University, Jinan 250000, P.R. China

*Corresponding authors: Tel: +86 18678770197, +86 13153034007; E-mail: mse_guanrf@ujn.edu.cn; zhouchuanjian@sdu.edu.cn

\begin{abstract}
In this paper, 1st-4th generation of carbosilane dendrimers $\left[\mathrm{G}_{1}(\mathrm{PhBr})-\mathrm{G}_{4}(\mathrm{PhBr})\right]$ were synthesized with bromophenyl group as a core molecule. Then, the inclusion reaction of $\alpha-, \beta-, \gamma$-cyclodextrin and four generations of carbosilane dendrimers mentioned above had been studied. The products were characterized by infrared spectroscopy, X-ray diffraction, nuclear magnetic resonance $\left({ }^{1} \mathrm{H},{ }^{13} \mathrm{C}\right.$ and $\left.{ }^{29} \mathrm{Si} \mathrm{NMR}\right)$. Results showed that each $\mathrm{G}_{1}(\mathrm{PhBr})$ would form inclusion complexes with two cyclodextrins molecules. The inclusion complexes of $\mathrm{G}_{2}(\mathrm{PhBr})$ and cyclodextrins were amphiphilic, while bromophenyl cores of $\mathrm{G}_{3}(\mathrm{PhBr})$ and $\mathrm{G}_{4}(\mathrm{PhBr})$ were entrapped by increasing "branches" made them more difficult to form inclusion complexes with the increasing generation of dendrimers, none of three kinds of cyclodextrins would form inclusion complexes with more than 2nd-generation dendrimers.
\end{abstract}

Key Words: Carbosilane, Dendrimers, Cyclodextrins, Inclusion complex.

\section{INTRODUCTION}

Carbosilane dendrimers are a series of branched threedimensional macromolecules with supple molecular chains, smaller intermolecular force, as well as good flowability even if the generation is high. At the same time, they are inert in physiology and good at biocompatibility. The carbosilane dendrimers with these characteristics have a broad application prospects $^{1,2}$. Carbosilane dendrimers have a wide variety of structures, both end groups and cores can be functionalized for further researches and applications. Generally, polyfunctional chlorosilane and alkoxysilane are often used as a core $\left(\mathrm{SiCl}_{4} \text { and } \mathrm{RSiCl}_{3}\right)^{3,4}$. Bromophenyl group is active to react with other regents to introducing functionalized groups or constructing more complicated structures, the reduced structural density of carbosilane dendrimers in the intramolecular core is amenable to host-molecule entrapment with opportunities for subsequent controlled release. However, there is no report about carbosilane dendrimers with bromophenyl group as a core so far.

Cyclodextrins (CDs), a family of cup-shaped hollow oligosaccharides give a hydrophobic cavity and hydrophilic exterior, are widely-recognized in supramolecular chemistry as hosts ${ }^{5}$. Cyclodextrins can include geometrical compatible polymer to give inclusion complexes and the stability of such rigid supramolecular rods mainly depends on non-covalent interactions of driving inclusion, such as hydrogen bonding among cyclodextrins as well as hydrophobic interactions between the inner cyclodextrin host and polymer guest ${ }^{6}$. The rigid supramolecular rods further aggregate spontaneously into "channel-type" crystals which usually precipitate from aqueous solution and the polarity of many molecular chains can be modified in a regioselective manner by forming inclusion complexes $^{7,8}$.

Then, 1st-4th generation of carbosilane dendrimers with 3-( $p$-bromophenyl)-propylene group as cores were synthesized via hydrosilylation and an alkylation reaction of allyl magnesium bromide Grignard reagent. Furthermore, a series of cyclodextrin/dendrimers inclusion complexes had been self-organized based on the assembly strategy induced by hostguest recognition. As a result, the hydrophilicity of dendrimers increased and the amphiphilicity of whole molecules changed which influence the aggregation morphologies of final product. The morphology and inclusion sites of different generational carbosilane dendrimers in the cyclodextrins solution had been studied.

\section{EXPERIMENTAL}

Raw material: $\alpha$-Cyclodextrin, $\beta$-cyclodextrin and $\gamma$ cyclodextrin (WACKER Chemie AG, Germany) were used 
after recrystallization. Allyl bromide, magnesium powder and methyldichlorosilane were Aldrich product, used directly without purification. Ether was dried by distillation from the blue solution of sodium-benzophenone ketyl under a static pressure of dried argon atmosphere. Dichloro triphenylphosphonium nickel $\left[\mathrm{Ni}\left(\mathrm{PPh}_{3}\right)_{2} \mathrm{Cl}_{2}\right]$ was dried by distillation under a static pressure of dried Ar atmosphere. Hexane was dried and distilled by metal sodium. Spier catalyst was provided by Shandong University. Ammonium chloride and anhydrous magnesium were commercially available.

Characterization: NMR spectra were recorded on Bruker-Avance-600 Spectrometer in $\mathrm{D}_{2} \mathrm{O}$, with $\mathrm{Me}_{4} \mathrm{Si}$ as internal standard. FT-IR spectra were measured by Nicolet 380 with the $\mathrm{KBr}$ tablet or $\mathrm{KBr}$ tablet coating. XRD analyses were obtained on D8-ADVANCE (Brucker).

\section{Synthesis of dendrimers}

Synthesis of allyl bromide Grignard reagent: $\operatorname{Mg}(0.264$ $\mathrm{g}, 11 \mathrm{mmol})$ and anhydrous ether $(30 \mathrm{~mL})$ were added under argon atmosphere and then a mixture of redistilled allyl bromide $(1.21 \mathrm{~g})$ and dehydrated degassed diethyl ether $(20 \mathrm{~mL})$ were slowly added to keep the reaction solution slightly boiling. The reaction continued for $5 \mathrm{~h}$ after adding all diethyl ether. The product, allyl bromide Grignard reagent, was obtained and kept for future use.

Bromophenyl propylene: A mixture of dibromobenzene (11.8 g, $50 \mathrm{mmol}), \mathrm{Mg}$ powder (1.32 g) and anhydrous ether
$(100 \mathrm{~mL})$ were added under Ar, stirred at room temperature, then $\mathrm{I}_{2}(0.01 \mathrm{~g})$ was added. To prevent over reaction, cooling the reactor at times by ice-salt bath until the reaction stabilized. The reaction mixture were stirred for $2 \mathrm{~h}$ at room temperature and refluxed for $1 \mathrm{~h}$, then cooled to room temperature. The solution was transferred to a dried dropping funnel under $\mathrm{Ar}$ and a mixture of allyl bromide $(9.74 \mathrm{~g})$ and $\mathrm{Ni}\left(\mathrm{PPh}_{3}\right)_{2} \mathrm{Cl}_{2}(3.3$ $\mathrm{mg}$ ) were added slowly in diethyl ether $(50 \mathrm{~mL})$ at room temperature. The reaction mixture were stirred for $2 \mathrm{~h}$ and refluxed for $48 \mathrm{~h}$. Solvent was distilled off under vacuum when the reaction was completed, b.p. $110-113^{\circ} \mathrm{C} / 1$ torr fractions were collected. The product was colourless liquid with special smell, yield: $7.01 \mathrm{~g}(70.0 \%)$.

Synthesis various generations of carbosilane dendrimers with bromophenyl group as a core molecule (preparation of $\mathrm{G}_{1}(\mathrm{PhBr}), \mathrm{G}_{2}(\mathrm{PhBr}), \mathrm{G}_{3}(\mathrm{PhBr}), \mathrm{G}_{4}(\mathrm{PhBr})$ ).

Synthesis of $\mathbf{G}_{\mathbf{1}}(\mathbf{P h B r})$ : A mixture of compound $\mathbf{1}$ (Scheme-I) (3.93 g, $20 \mathrm{mmol})$ and dehydrated hexane (5 mL) were added to a dried Kontes tube under Ar, then Spier catalyst (5 drops) and methyldichlorosilane (5.52 g, $4.80 \mathrm{~mL}, 48 \mathrm{mmol}$ ) were added, the reaction mixture were stirred at $80{ }^{\circ} \mathrm{C}$ overnight. Unreacted components and solvent were evaporated carefully under reduced pressure to give product $\mathbf{2}$ (SchemeI). The residue was dissolved in dehydrated degassed diethyl ether $(20 \mathrm{~mL})$ and then transferred to a round-bottomed flask under argon atmosphere, cooled in an ice bath with stirring.<smiles>CCCCC(C)CBr</smiles>
Ni]<smiles>C=CCc1ccc(Br)cc1</smiles>

1<smiles>CCCCCCCCC</smiles><smiles>CN(C)CCCc1ccc(Br)cc1</smiles>

2<smiles>C=CC[Si](CC=C)(CC[Si](C)(CCCc1ccc(Br)cc1)CC[Sn](C)(CC=C)CC=C)CC(C)(C)C</smiles>

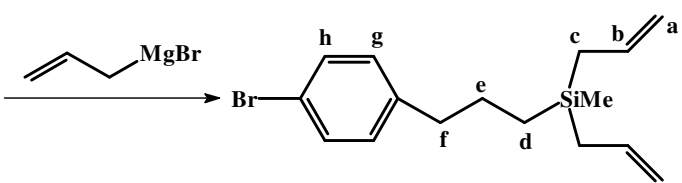

$\mathrm{G}_{\mathbf{1}}(\mathrm{PhBr})$

3

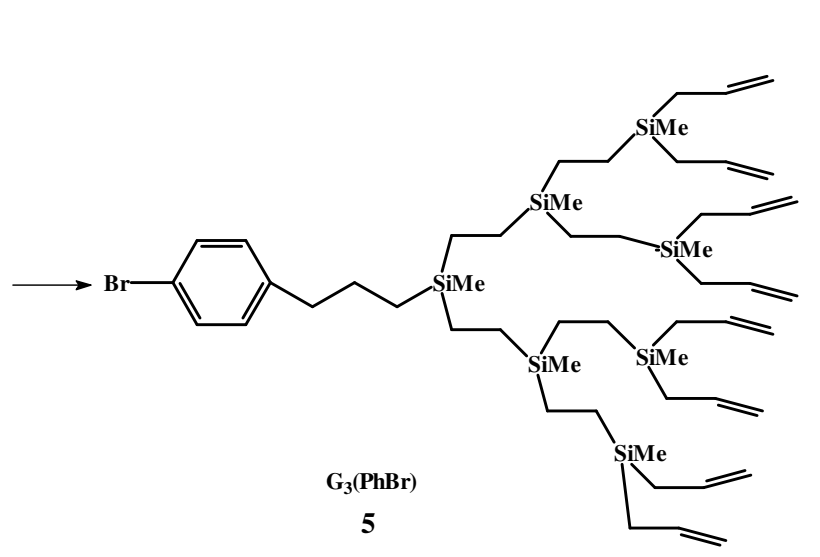

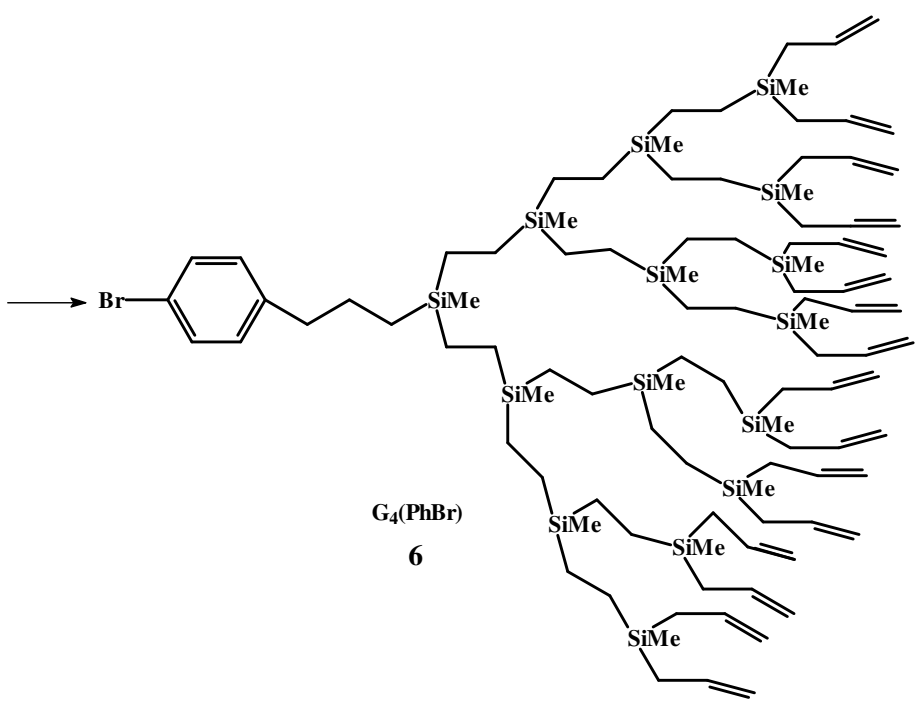


At the same time, corresponding amount of allyl Grignard reagent (molar ratio was 1:6) which was synthesized as described previously was added dropwise, ice bath was removed after the addition was finished. The reaction was terminated with $50 \mathrm{~mL}$ of $30 \% \mathrm{NH}_{4} \mathrm{Cl}$ solution in an ice-salt bath after 4 $\mathrm{h}$ at room temperature. The organic layer was washed by adding $20 \mathrm{~mL}$ of water and the water layer was extracted with diethyl ether $(3 \times 20 \mathrm{~mL})$. All of the organic layers were washed with ice water and dried over anhydrous $\mathrm{MgSO}_{4}$, the solvent was distilled off under vacuum after filtration. Distillation in $b p$ $100-140^{\circ} \mathrm{C} / 2$ torr, the residue was purified by column chromatography with hexane/ethyl ether $(40: 1) . \mathrm{G}_{1}(\mathrm{PhBr})$ was colourless oil with special smell, yield: $5.21 \mathrm{~g}(81.2 \%)$.

Synthesis of $\mathbf{G}_{\mathbf{2}}(\mathbf{P h B r})$ : This compound was prepared using a similar method to that described for $\mathrm{G}_{1}(\mathrm{PhBr})$, starting from compound $\mathbf{3}$ (Scheme-I)(3.23 g, $10 \mathrm{mmol})$ and dehydrated hexane $(5 \mathrm{~mL})$ were added to a dried Kontes tube under Ar to obtain compound $\mathrm{G}_{2}(\mathrm{PhBr})$ as a colourless oil with slight smell, yield: $3.43 \mathrm{~g}(60.1 \%)$.

Synthesis of $\mathbf{G}_{3}(\mathbf{P h B r})$ : This compound was prepared using a similar method to that described for $\mathrm{G}_{1}(\mathrm{PhBr})$, starting from compound 4 (Scheme-I) $(2.88 \mathrm{~g}, 5 \mathrm{mmol})$ and dehydrated hexane $(5 \mathrm{~mL})$ were added to a dried Kontes tube under Ar to obtain compound $\mathrm{G}_{3}(\mathrm{PhBr})$ as a colourless and odorless oil, yield: $2.74 \mathrm{~g}(51.3 \%)$.

Synthesis of $\mathbf{G}_{\mathbf{4}}(\mathbf{P h B r})$ : This compound was prepared using a similar method to that described for $\mathrm{G}_{1}(\mathrm{PhBr})$, starting from compound 5 (Scheme-I) $(2.69 \mathrm{~g}, 2.5 \mathrm{mmol})$ and dehydrated hexane $(5 \mathrm{~mL})$ were added to a dried Kontes tube under Ar to obtain compound $\mathrm{G}_{4}(\mathrm{PhBr})$ as a colourless and odorless oil, yield: $2.25 \mathrm{~g}(45.3 \%)$.

Synthesis of inclusion complexes of carbosilane dendrimers with bromophenyl group as a core molecule and cyclodextrins: According to compositions shown in Table-1, corresponding amount of carbosilane dendrimers with bromophenyl group as a core molecule $\left[\mathrm{G}_{1}(\mathrm{PhBr})\right.$ to $\left.\mathrm{G}_{4}(\mathrm{PhBr})\right]$ were added dropwise to a saturated solution of $\alpha$-cyclodextrin $\left(20^{\circ} \mathrm{C}\right.$ solubility of $\left.90 \mathrm{mg} / \mathrm{gH}_{2} \mathrm{O}\right), \beta$-cyclodextrin $\left(20^{\circ} \mathrm{C}\right.$ solubility of $\left.16.4 \mathrm{mg} / \mathrm{gH}_{2} \mathrm{O}\right)$ and $\gamma$-cyclodextrin $\left(20^{\circ} \mathrm{C}\right.$ solubility of $185 \mathrm{mg} / \mathrm{gH}_{2} \mathrm{O}$ ), treated with ultrasonic $15 \mathrm{~min}$ at room temperature to give the inclusion complexes of $\mathrm{G}_{\mathrm{n}}(\mathrm{PhBr})$ and $\alpha$-cyclodextrin $\left(\mathrm{BG}_{\mathrm{n}}-\alpha\right)$, inclusion complexes of $\mathrm{G}_{\mathrm{n}}(\mathrm{PhBr})$ and $\beta$-cyclodextrin $\left(B_{\mathrm{n}}-\beta\right)$, inclusion complexes of $\mathrm{G}_{\mathrm{n}}(\mathrm{PhBr})$ and $\gamma$-cyclodextrin $\left(\mathrm{BG}_{\mathrm{n}}-\gamma\right)$ (where $\mathrm{n}$ varies from 1 to 4 ).

\section{RESULTS AND DISCUSSION}

$\mathbf{G}_{\mathbf{1}}$ (PhBr): ${ }^{1} \mathrm{H}$ NMR $(\delta \mathrm{ppm}):$ 7.42-7.40 (d, 2H, H-g), 7.08-7.05 (d, 2H, H-h), 5.86-5.67(m, 2H, H-b), 4.91-4.88 (d, $2 \mathrm{H}, \mathrm{H}-\mathrm{a}), 4.82$ (s, 2H, H-a), 2.62-2.57(t, 2H, H-f), 1.58-1.56 (d, 6H, H-c, H-d), 1.42-1.25(m, 2H, H-e), 0.00(s, 3H, H-i); ${ }^{13} \mathrm{C}$ NMR $(\delta \mathrm{ppm}) 141.3,134.6(\mathrm{~b}), 131.3,130.2,119.4$, 113.3(a), 39.2(f) , 25.6(e), 21.3(c), 12.8(d), -5.8(i); ${ }^{29} \mathrm{Si}$ NMR ( $\delta$ ppm) 0.94; $\mathrm{C}_{16} \mathrm{H}_{23} \mathrm{BrSi}, \mathrm{Mw} 323$.

$\mathbf{G}_{\mathbf{2}}$ (PhBr): ${ }^{1} \mathrm{H}$ NMR $(\delta \mathrm{ppm}): 7.42-7.40(\mathrm{~d}, 2 \mathrm{H}, \mathrm{Ar}-\mathrm{H})$, 7.08-7.05 (d, 2H, Ar-H), 5.86-5.68 (m, 4H, DB-H), 4.914.88(d, 4H, DB- $\left.\mathrm{H}_{2}\right), 4.83\left(\mathrm{~s}, 4 \mathrm{H}, \mathrm{DB}-\mathrm{H}_{2}, \mathrm{DB}-\mathrm{H}_{2}\right), 2.60-2.57(\mathrm{t}$, $\left.2 \mathrm{H}, \mathrm{Ar}-\mathrm{CH}_{2}\right), 1.61-1.58$ (d, 8H, DB- $\left.\mathrm{CH}_{2}\right), 1.42-1.28(\mathrm{~m}, 8 \mathrm{H})$, 0.98-0.96 (t, 2H, $\mathrm{CH}_{2}$ ), 0.61-0.42 (m, 8H, Si-CH ${ }_{2}$ ), 0.00(s, $\left.9 \mathrm{H}, \mathrm{Si}-\mathrm{CH}_{3}\right) ;{ }^{13} \mathrm{C}$ NMR $(\delta \mathrm{ppm}): 141.5,132.8,131.2,119.3$, $113.1,39.4,25.99,21.5,18.6,12.2,17.9,13.7,-5.1,-5.7 ;{ }^{29} \mathrm{Si}$ NMR $\left(\delta\right.$ ppm): 1.71, 0.22; $\mathrm{C}_{30} \mathrm{H}_{51} \mathrm{BrSi}_{3}, \mathrm{Mw} 575$.

$\mathbf{G}_{3}(\mathbf{P h B r}):{ }^{1} \mathrm{H}$ NMR $(\delta \mathrm{ppm}): 7.41-7.39$ (d, 2H, Ar-H), 7.10-7.03(d, 2H, Ar-H), 5.88-5.71 (m, 8H, DB-H), 4.954.80(m, 16H, DB- $\left.\mathrm{H}_{2}\right), 2.61-2.57\left(\mathrm{t}, 2 \mathrm{H}, \mathrm{Ar}-\mathrm{H}_{2}\right), 1.64-1.53$ (d, 16H, DB-H $\left.{ }_{2}\right), 1.41-1.20\left(\mathrm{~m}, 16 \mathrm{H}, \mathrm{CH}_{2}\right), 1.028-0.80(\mathrm{~m}, 4 \mathrm{H}$, $\left.\mathrm{CH}_{2}\right), 0.71-0.42\left(\mathrm{~m}, 16 \mathrm{H}, \mathrm{Si}-\mathrm{CH}_{2}\right), 0.00\left(\mathrm{~s}, 18 \mathrm{H}, \mathrm{Si}-\mathrm{CH}_{3}\right) ;{ }^{13} \mathrm{C}$ NMR $(\delta$ ppm)132.6, 131.2, 130.2, 113.5, 39.4, 26.0, 21.5, $18.8,18.3,18.0,-5.0,-4.9 ;{ }^{29} \mathrm{Si}$ NMR $(\delta \mathrm{ppm}) 1.65,0.98,0.24$; $\mathrm{C}_{58} \mathrm{H}_{107} \mathrm{BrSi}_{7}$, Mw1076.

$\mathbf{G}_{4}(\mathbf{P h B r}):{ }^{1} \mathrm{H}$ NMR $(\delta \mathrm{ppm}): 7.42-7.40(\mathrm{~d}, 2 \mathrm{H}, \mathrm{Ar}-\mathrm{H})$, 7.04-7.02 (d, 2H, Ar-H), 5.91-5.76 (m, 16H, DB-H), 4.96$4.84\left(\mathrm{~d}+\mathrm{s}, 32 \mathrm{H}, \mathrm{DB}-\mathrm{H}_{2}\right), 2.62-2.57\left(\mathrm{t}, 2 \mathrm{H}, \mathrm{Ar}-\mathrm{H}_{2}\right), 1.63-1.58$ (d, 32H, DB-H $)_{2}, 1.40-1.22\left(\mathrm{~m}, 32 \mathrm{H}, \mathrm{CH}_{2}\right), 1.00-0.84(\mathrm{~m}, 6 \mathrm{H})$, 0.64-0.50(m, 48H, Si-CH $), 0.01-0.08\left(\mathrm{~s}, 45 \mathrm{H}, \mathrm{Si}-\mathrm{CH}_{3}\right) ;{ }^{13} \mathrm{C}$ NMR $(\delta$ ppm): 135.6, 135.4, 131.3, 130.2, 113.0, 112.7, 21.5, 21.1, 18.9, 18.8, 18.5, 18.4, 18.3, 18.10, 18.0, -5.0, -5.1, -5.5; ${ }^{29} \mathrm{Si}$ NMR $(\delta \mathrm{ppm}): 1.64,0.98,0.69,0.23 ; \mathrm{C}_{114} \mathrm{H}_{211} \mathrm{BrSi}_{15}$, Mw2079.

Infrared spectroscopy analysis of $\mathbf{B G}_{\mathbf{1}}-\alpha$ : Fig. 1 from top to bottom shows the spectra of $\alpha$-cyclodextrin, $\mathrm{BG}_{1}-\alpha$ and $\mathrm{G}_{1}(\mathrm{PhBr})$. Compared with the spectra of $\alpha$-cyclodextrin, $B G_{1}-\alpha$ and $G_{1}(P h B r)$, the infrared spectra of $B G_{1}-\alpha$ is similar to that of $\alpha$-cyclodextrin.

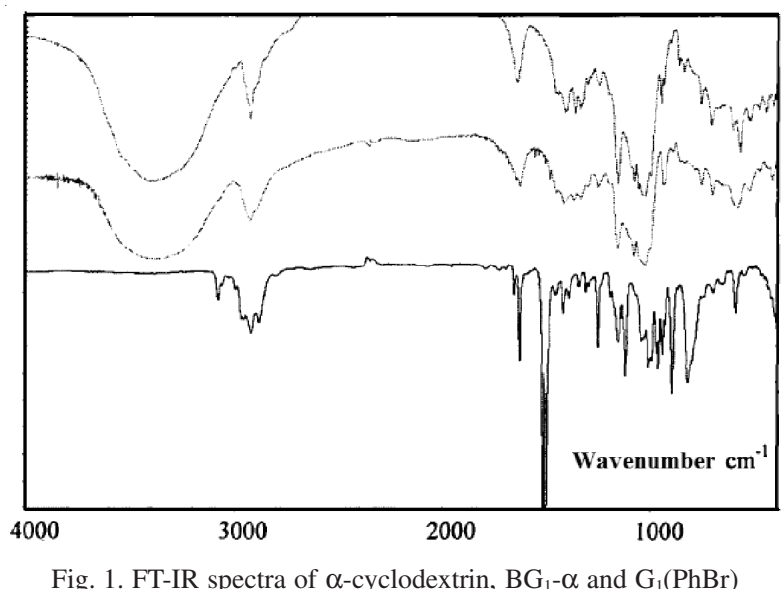

Fig. 1. FT-IR spectra of $\alpha$-cyclodextrin, $\mathrm{BG}_{1}-\alpha$ and $\mathrm{G}_{1}(\mathrm{PhBr})$

TABLE-1

COMPOSITIONS FOR SYNTHESIS OF INCLUSION COMPLEXES WITH MULTI-GENERATIONAL CARBOSILANE DENDRIMERS WITH BROMOPHENYL GROUP AS A CORE MOLECULE AND CYCLODEXTRINS

\begin{tabular}{lclclc} 
S. No. & $\alpha$-CD $(\mathrm{mmol})$ & S. No. & $\beta$-CD $(\mathrm{mmol})$ & S. No. & $\gamma$-CD (mmol) \\
\hline $\mathrm{BG}_{1}-\alpha$ & 0.37 & $\mathrm{BG}_{1}-\beta$ & 0.16 & $\mathrm{BG}_{1}-\gamma$ & 0.29 \\
$\mathrm{BG}_{2}-\alpha$ & 0.18 & $\mathrm{BG}_{2}-\beta$ & 0.087 & $\mathrm{BG}_{2}-\gamma$ & 0.15 \\
$\mathrm{BG}_{3}-\alpha$ & 0.18 & $\mathrm{BG}_{3}-\beta$ & 0.087 & $\mathrm{BG}_{3}-\gamma$ & 0.15 \\
$\mathrm{BG}_{4}-\alpha$ & 0.09 & $\mathrm{BG}_{4}-\beta$ & 0.044 & $\mathrm{BG}_{4}-\gamma$ & 0.15 \\
\hline
\end{tabular}

$\alpha$-CD-Mw:972, $\beta$-CD-Mw:1135, $\gamma$-CD-Mw:1297 G $\mathrm{G}_{1}(\mathrm{PhBr})-\mathrm{Mw}: 323, \mathrm{G}_{2}(\mathrm{PhBr})-\mathrm{Mw}: 575, \mathrm{G}_{3}(\mathrm{PhBr})-\mathrm{Mw}: 1076, \mathrm{G}_{4}(\mathrm{PhBr}) \mathrm{Mw}: 2079$. 


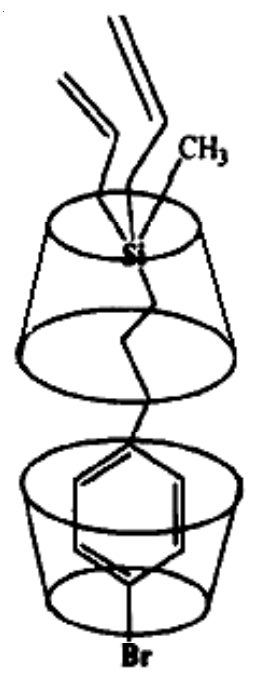

$\mathrm{G}_{1}(\mathrm{PhBr})$

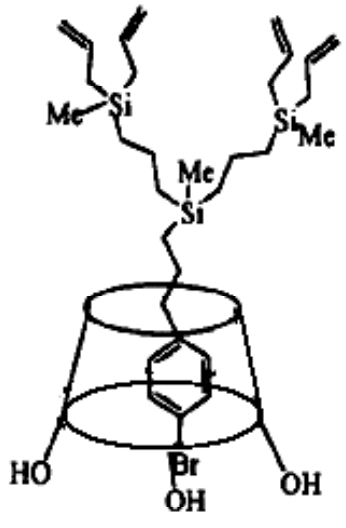

$\mathrm{G}_{\mathbf{2}}(\mathrm{PhBr})$
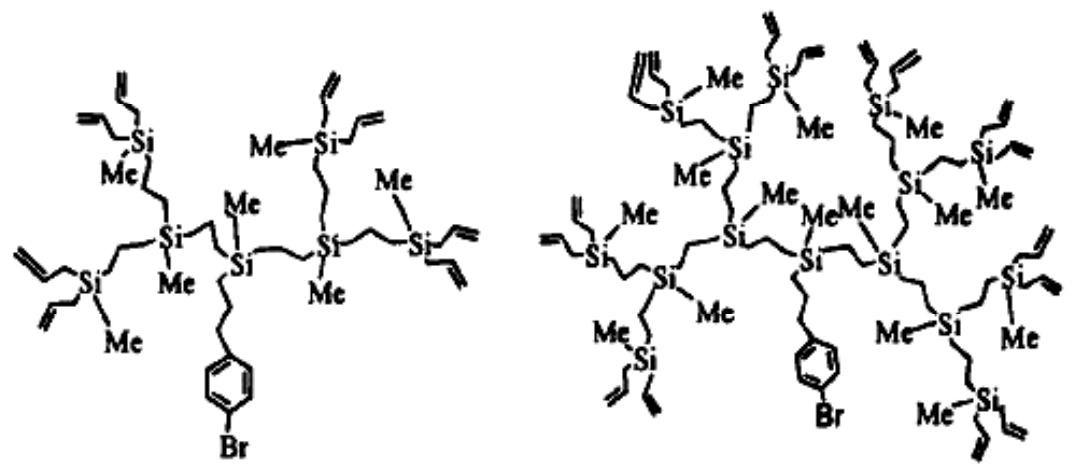

$\mathbf{G}_{\mathbf{3}}(\mathrm{PhBr})$
$\mathrm{G}_{\mathbf{4}}(\mathrm{PhBr})$

Fig. 2. Possible structures of different generational carbosilane dendrimers in cyclodextrins solution

The infrared absorption spectra of $\mathrm{BG}_{1}-\beta$ and $\mathrm{BG}_{1}-\gamma$ with corresponding cyclodextrins are similar to the case of $\mathrm{BG}_{1}-\alpha$. The peaks of inclusion complexes are similar to the corresponding cyclodextrins and the specific absorptions occur offsets in varying degrees. Such as the absorption peak at 1633 $\mathrm{cm}^{-1}$ of $\mathrm{BG}_{1}-\alpha$ is close to the double band absorption peak at $1630 \mathrm{~cm}^{-1}$ of $\mathrm{G}_{1}(\mathrm{PhBr})$, which is different from the absorption peak at $1642 \mathrm{~cm}^{-1}$ of $\alpha$-cyclodextrin. In addition, the absorption peak at $1251 \mathrm{~cm}^{-1}$ of $\mathrm{Si}_{-} \mathrm{CH}_{2}$ in $\mathrm{BG}_{1}-\alpha$ is close to the absorption peak at $1258 \mathrm{~cm}^{-1}$ of $\mathrm{G}_{1}(\mathrm{PhBr})$, while $\alpha$-cyclodextrin has no corresponding absorption peak. The results of infrared spectroscopy preliminary represent that $\mathrm{BG}_{1}-\beta$ and $\mathrm{BG}_{1}-\gamma$ form the inclusion complexes.

With increasing generation, the final production of reaction system varies from precipitation, turbid solution and turbidity solution with oil layer. The possible structures of different generational carbosilane dendrimers in cyclodextrins solution are illustrated in Fig. 2. The precipitate here is inclusion complexes of $\mathrm{G}_{1}(\mathrm{PhBr})$ and cyclodextrins. "Branches" of $\mathrm{G}_{2}(\mathrm{PhBr})$ grow too big to form inclusion complexes with cyclodextrins, while the bromophenyl cores can form inclusion complexes with cyclodextrins. Such a structure which is similar to the amphiphilic structure of surfactants can form micelles and oily $\mathrm{G}_{2}(\mathrm{PhBr})$ compatibilize in it, as a result, $\mathrm{G}_{2}(\mathrm{PhBr})$ in cyclodextrins solution is emulsifiable. In the case of $\mathrm{G}_{3}(\mathrm{PhBr})$ and $\mathrm{G}_{4}(\mathrm{PhBr})$, "branches" further growth as well as the generations become higher. Bromophenyl cores are entrapped by "branches", making it hard to form inclusion complexes with cyclodextrins. Because of both ends of $\mathrm{G}_{3}(\mathrm{PhBr})$ and $\mathrm{G}_{4}(\mathrm{PhBr})$ are hydrophobic, eventually $\mathrm{G}_{3}(\mathrm{PhBr})$ and $\mathrm{G}_{4}(\mathrm{PhBr})$ separate from aqueous phase, floating on the surface of the solution.

XRD analysis of $\mathbf{B G}_{\mathbf{1}}-\boldsymbol{\alpha}, \mathbf{B G}_{\mathbf{1}}-\boldsymbol{\beta}$ and $\mathbf{B G}_{\mathbf{1}}-\boldsymbol{\gamma}$ : Fig. 3 shows

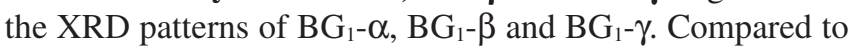
the XRD patterns of three inclusion complexes, in general, the diffraction peaks are wider and closer to the diffraction peaks of amorphous polymer, like flat "steamed bread".

Figs. 4-6 show the XRD patterns of $\mathrm{BG}_{1}-\alpha, \mathrm{BG}_{1}-\beta$ and $\mathrm{BG}_{1}-\gamma$ with corresponding cyclodextrins, respectively. The

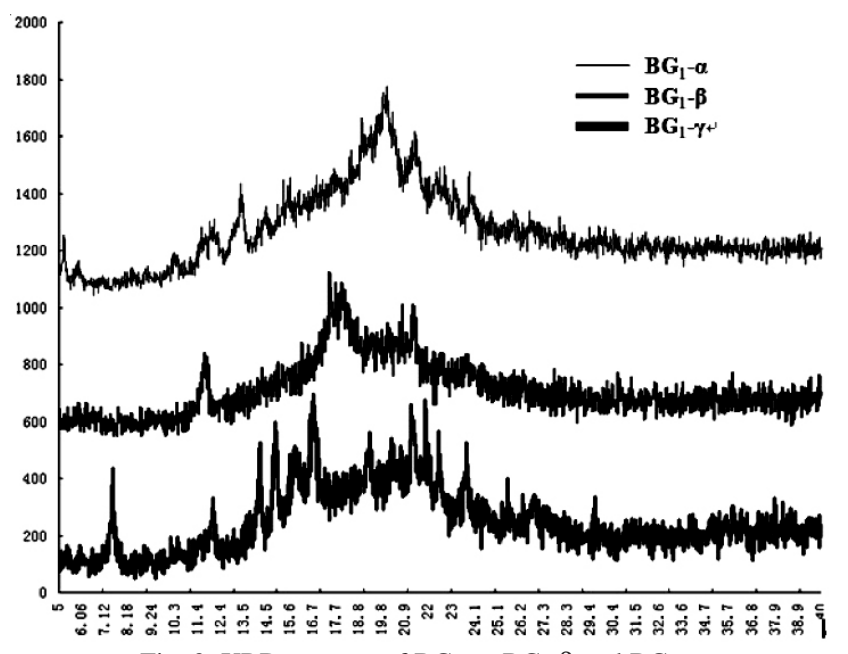

Fig. 3. XRD patterns of $\mathrm{BG}_{1}-\alpha, \mathrm{BG}_{1}-\beta$ and $\mathrm{BG}_{1}-\gamma$

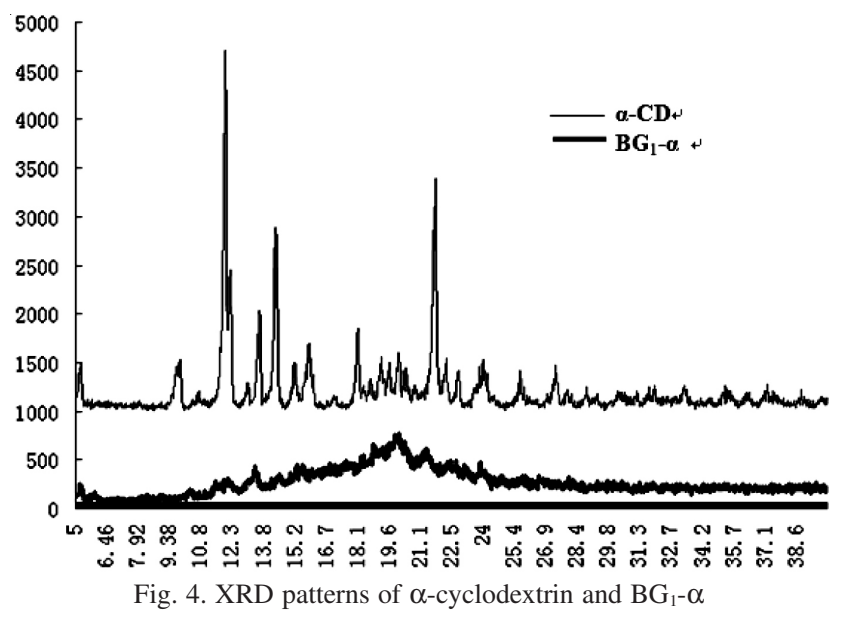

three figures imply the same conclusion: the crystallization of inclusion complexes are far less perfect than the corresponding cyclodextrins crystal; the crystallization of inclusion complexes are different from the corresponding cyclodextrins which reflect not only on the peak intensity of diffractions but also on the trend of the peaks. 

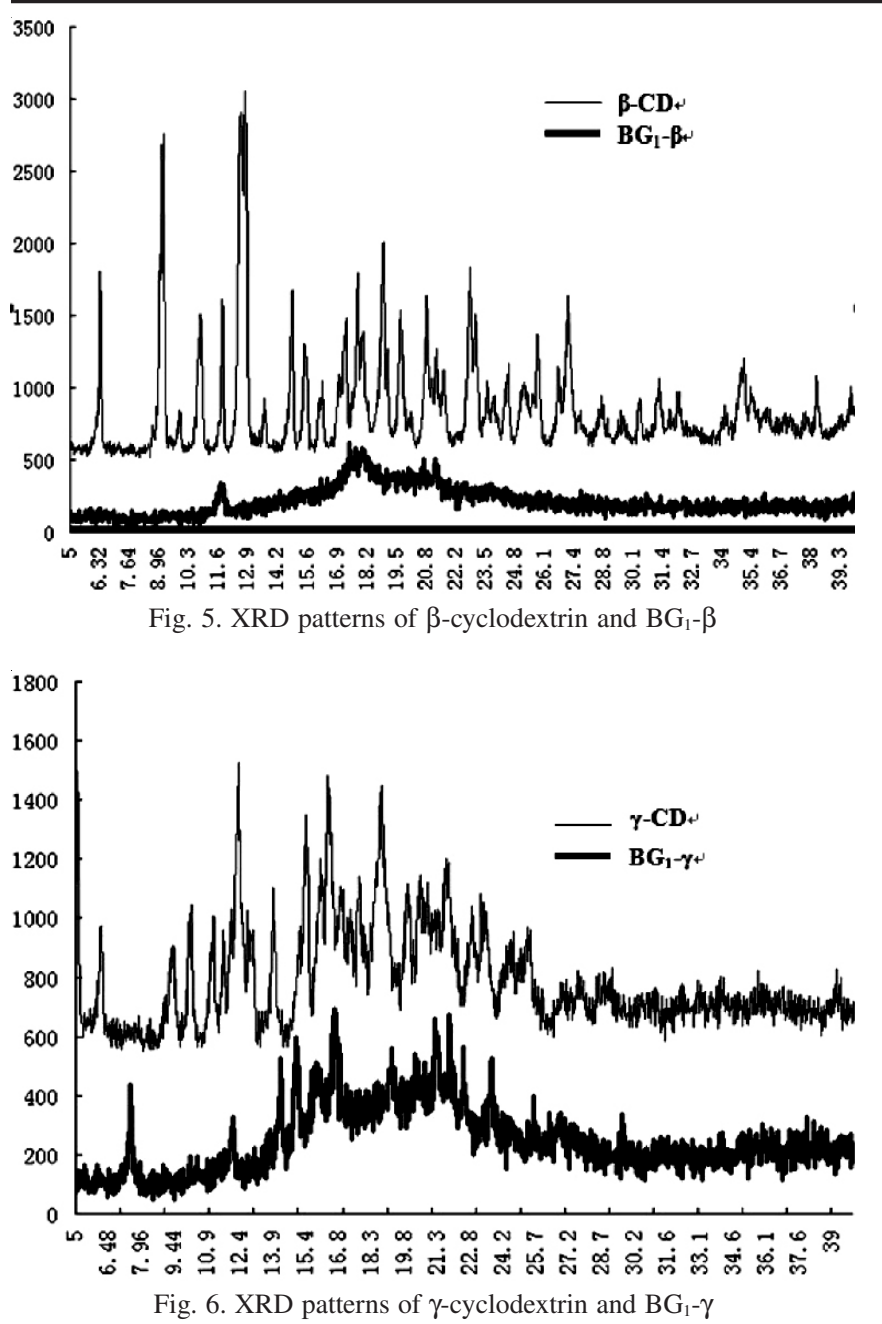

${ }^{1} \mathbf{H}$ NMR analysis of $\mathbf{B G}_{\mathbf{1}}-\boldsymbol{\alpha}$ and $\mathbf{B G}_{\mathbf{1}}-\beta$ : In the $\mathrm{BG}_{1}-\alpha$, $\mathrm{H}-3$ of the $\alpha$-cyclodextrin moves from 3.57-3.81 ppm, H-5 moves from 3.39-3.49 ppm, signaling that a inclusion complex has been formed with cyclodextrins and carbosilane dendrimers. In addition, integral results of $5.42 \mathrm{ppm}(\mathrm{m}, 2 \mathrm{H}$, $\left.\mathrm{G}_{1}(\mathrm{PhBr})-\mathrm{H}-\mathrm{b}\right)$ and $4.90 \mathrm{ppm}(\mathrm{s}, 6 \mathrm{H}, \alpha-\mathrm{CD}-\mathrm{H}-1)$ show that the proportion of $\alpha$-cyclodextrin and $\mathrm{G}_{1}(\mathrm{PhBr})$ in the inclusion complex is $2: 1$. The structure of $\mathrm{BG}_{1}-\alpha$ molecular is shown in Fig. 7.
Similar to the $\mathrm{BG}_{1}-\alpha$, the ${ }^{1} \mathrm{H}$ NMR analyses of $\mathrm{BG}_{1}-\beta$ and $\mathrm{BG}_{1}-\gamma$ show that the ratio of cyclodextrins with $\mathrm{BG}(\mathrm{PhBr})$ is about 2:1.

\section{Conclusion}

In this paper, carbosilane dendrimers $\left[\mathrm{G}_{1}(\mathrm{PhBr})-\mathrm{G}_{4}(\mathrm{PhBr})\right]$ are synthesized with bromophenyl group as a core molecule, then the inclusion complexes of $\alpha-, \beta-, \gamma$-cyclodextrin and four generations of carbosilane dendrimers have been studied and the following conclusions can be drawn: Various generation of carbosilane dendrimers with bromophenyl group as a core can be synthesized successfully by an iterative procedure and the structure is the same as designed. All of three cyclodextrins and 1st-generation dendrimers can form inclusion complexes, which include a dendrimer and two cyclodextrins molecules. With the generation increasing, the reaction of inclusion becomes more and more difficult. The aqueous solution of cyclodextrins with the 2nd-generation dendrimer compound appears turbid during the reaction; none of three kinds of cyclodextrins can form inclusion complexes with more than 2nd-generation dendrimers.

\section{ACKNOWLEDGEMENTS}

This work was supported by the Scientific Research Foundation for the Outstanding Young Scientist of Shandong Province BS2010CL006 and BS2010CL026.

\section{REFERENCES}

1. I. Cuadrado, M. Morán, C.M. Casado, B. Alonso and J. Losada, Coord. Chem. Rev., 193-195, 395 (1999).

2. C.K. Kim and J.H. Hong, Molecules, 14, 3719 (2009).

3. A.W. van der Made and P.W.N.M. van Leeuwen, J. Chem. Soc., Chem. Commun., 1400 (1992).

4. D. Seyferth, D.Y. Son, A.L. Rheingold and R.L. Ostrander, Organometallics, 13, 2682 (1994).

5. J. Wang and M. Jiang, J. Am. Chem. Soc., 128, 3703 (2006).

6. J. Huang, L.X. Ren, H. Zhu and Y.M. Chen, Macromol. Chem. Phys., 207, 1764 (2006)

7. L.X. Ren, F.Y. Ke, Y.M. Chen, D.H. Liang and J. Huang, Macromolecules, 41, 5295 (2008).

8. J. Huang, L.X. Ren and Y.M. Chen, Polym. Int., 57, 714 (2008).

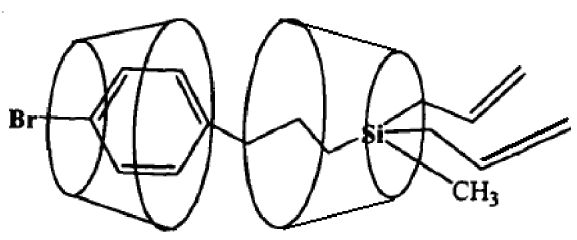

Fig. 7. Structure of $\mathrm{BG}_{1}-\alpha$ molecular 